\title{
Comorbidities in multiple sclerosis-a plea for interdisciplinary collaboration to improve the quality of life of MS patients
}

This article was published in the following Dove Press journal:

Degenerative Neurological and Neuromuscular Disease

\author{
Hans-Klaus Goischke \\ Independent Researcher, Bad Brückenau, \\ Bavaria, Germany
}

\begin{abstract}
The negative influence of comorbidities on the quality of life of people with multiple sclerosis is evident and the problem is increasingly acknowledged by numerous international studies in long-term care. One therapeutic option would be an add-on therapy with vitamin D (VD), with the aim of achieving a therapeutically effective dose. The individually required VD dose must be tested, since the response to a certain dose is subject to variations between individuals. A possible toxicity with increased 1.25(OH)D3 (active VD metabolite) is largely prevented by increased activity of 24-hydroxylase (CYP24A1). Monitoring of serum VD levels as well as serum calcium and phosphate levels (optional $\mathrm{Ca}$ excretion in 24-hour urine, Ca creatinine ratio in urine) provides safety and is necessary because possible mutations on the (catabolic) CYP24A1 gene can lead to a partial or total loss of 24-hydroxylase activity and provoke hypercalcemia/hyperphosphatemia. The main therapeutic objective is to maintain functional and social independence by using drugs with a high safety profile. The prevention and optimal management of comorbidities can influence the quality of life of patients with MS (PwMS) when included in patient care. Adequate measures can reduce the burden of MS only if the risk of comorbidity is reduced through targeted monitoring, early detection and diagnosis. Such a strategy will contribute to influencing the premature mortality of patients with MS. If VD is recognized as a "multipurpose steroid hormone", it could also be used to maintain cognitive function and prevent premature possible dementia, especially as there is evidence that VD deficiency correlates with brain atrophy (hippocampus). At present, MS therapy is still a balancing act between therapeutically efficient action and the management of unexpected side effects, with VD addon therapy being almost unproblematic and most likely to be accepted by PwMS.
\end{abstract}

Keywords: comorbidities in multiple sclerosis, improving quality of life, vitamin D therapy, pregnancy in MS

\section{Introduction}

The care of people with multiple sclerosis (PwMS) requires coordinated, multidisciplinary treatment, as it has been shown in practice that care is mainly provided by general practitioners and neurologists in private practice rather than by specialized multiple sclerosis (MS) centers. In Germany, more than 200,000 people suffer from MS. ${ }^{1}$ Awareness of the high prevalence of comorbidities (Tables 1-3) and the evidence that these also influence the progression, cognition and quality of life of PwMS and increase premature mortality ${ }^{2}$ indicates that these diseases must be appropriately prevented and managed. ${ }^{3}$ This aspect is now included in the current
Correspondence: Hans-Klaus Goischke D-97769 Bad Brückenau, Hochwaldstr.2, Bavaria, Germany

Tel +4997412748

Email hkem.goischke@t-online.de 
Table I Lifetime prevalence rates of comorbidities in PwMS

\begin{tabular}{|l|l|}
\hline Major depressive disorder & $36-54 \%^{16,127}$ \\
Anxiety disorders & $35.7 \%^{16,127}$ \\
Bipolar disorder & $13 \%^{127}$ \\
Adjustment disorders & $22 \%^{127}$ \\
Psychotic disorders & $2-3 \%^{128}$ \\
\hline
\end{tabular}

Abbreviaton: PwMS, people with multiple sclerosis.

2017 European Therapeutic Guidelines. ${ }^{4}$ All therapists must be sensitized to the occurrence of comorbidities (CM) (including depression, anxiety, hyperlipidemia, migraine and anemia) before MS symptoms are registered. ${ }^{5}$ In addition to "primary therapy" (course-modifying immunotherapeutics=disease-modifying treatment; DMTs) of relapsing-remitting multiple sclerosis (RRMS) with the aim of stopping progression, the best possible maintenance of quality of life is an essential target parameter. At present, however, there are no biomarkers in individual drug therapy planning which can predict the efficacy of the intended drug. The future determination of osteopontin (OPN) and serum neurofilament light chains (sNfL) in peripheral blood as valid biomarkers for diagnosis and prognosis would be a milestone in the treatment of PwMS with RRMS. When MS therapy has been effective, sNfL levels decrease approximately 3-6 months later. ${ }^{6}$ Despite consideration of disease activity and the current European guidelines for drug therapy (14 drugs will be available for RRMS in the future), a period of "trial and error" is possible for PwMS. For example, six of the drugs used for the basic treatment of relapse reduction in RRMS achieve an absolute risk reduction of about $30-45 \%$.

However, the almost daily increase in knowledge about the "influence of vitamin D (VD) on the course of multiple sclerosis and on comorbidities" allows practitioners to strive for an adequate VD level in all PwMS, despite controversial discussions about the dose level in VD supplementation. It is undisputed that PwMS want "complementary or alternative therapies" to prevent their disease from worsening. ${ }^{7}$ The physician-patient relationship is positively influenced by the possibility of other therapies in addition to basic or escalation therapy.

In routine diagnostics, no genetic risk factors (eg HLA DRB1*1501) or variants of the genes of the vitamin D metabolizing enzymes 1-alpha-hydroxylase have been determined (rs12368653, rs10876994, rs118204009, rs10877013, rs703842 in CYP27B1), variations in CYP2R1 (encodes the enzyme responsible for the 25 hydroxylation of VD) and rs2248359 in CYP24A1, CYP2R1, DHCR7, GC and $C Y P 27 B 1)$. Because a selection of patients is not possible, a

Table 2 Variations in the prevalence of selected comorbidities in PwMS (eg depending on observation period, location and age of PwMS, gender, lifestyle factors, socioeconomic status, etc)

\begin{tabular}{|c|c|}
\hline Depression & $17.5-50 \% \%^{3,20,33,134-138}$ \\
\hline Anxiety & $21.9-54.1 \% 3,33,90,134$ \\
\hline Mood and anxiety disorders & $35.8 \%^{18}$ \\
\hline Bipolar disorders & $2.6 \%^{135}$ \\
\hline Psychoses & $4.3 \%{ }^{20}$ \\
\hline Hypertension & $10,5-29,7 \%$ 3,33,135,139 \\
\hline Psoriasis & $4-7.74 \%{ }^{20,124}$ \\
\hline Thyroid diseases & $2.08-18.5 \%^{20,79,140}$ \\
\hline Hashimoto's thyroiditis & $(0-16.1 \%)$, Graves' disease $\left.(0-2.56 \%)^{20}\right], 12.9-17.1 \%^{139}$ \\
\hline Diabetes mellitus (type I) & $10.5 \%^{140}$ \\
\hline Diabetes mellitus (type 2) & $4.9 \%^{124}$ \\
\hline Reduced bone mineral density (observed over 17 years) & $74.7-80 \%^{43}$ \\
\hline \multicolumn{2}{|c|}{ Women: $38 \%$ osteopenia, $44 \%$ osteoporosis, men $43 \%$ osteopenia, $37 \%$ osteoporosis. ${ }^{40}$} \\
\hline Cardiovascular diseases & $2.3-2.6 \%{ }^{134,135}$ \\
\hline Anemia, other blood disorders & $6.4-16 \% \%^{1,27,77}$ \\
\hline Hyperlipidemia & $10.9-25 . \% 3,33,139,141$ \\
\hline Migraine & $18.1 \%^{33}$ \\
\hline Chronic lung diseases & $10-12,1 \%{ }^{3,28}$ \\
\hline Asthma & $5-12.9 \%^{36,124}$ \\
\hline Pain & $20-90 \%{ }^{93}$ \\
\hline
\end{tabular}

Abbreviation: PwMS, people with multiple sclerosis. 
Table 3 Frequency of selected comorbidities in routine clinic visits in 949 Canadian mutiple sclerosis patients in 2010-201 I

\begin{tabular}{|l|l|l|}
\hline 1 & Depression & $(29 \%)$ \\
2 & Hypertension & $(17.8 \%)$ \\
3 & Migraine & $(17.3 \%)$ \\
4 & Hyperlipidemia & $(12,4 \%)$ \\
5 & Anxiety & $(11,5 \%)$ \\
6 & Chronic obstructive lung disease & $(9.8 \%)$ \\
7 & Irritable bowel syndrome & $(7.9 \%)$ \\
8 & Thyroid diseases & $(7.8 \%)$ \\
9 & Osteoporosis & $(6 \%)$ \\
\hline
\end{tabular}

Notes: Reprinted from Multiple Sclerosis and Related Disorders, 4, KM Fiest, JD Fisk, SB Patten, H Tremlett, C Wolfson, S Warren, KA McKay, L Berrigan, RA Marrie, Comorbidity is associated with pain-related activity limitations in multiple sclerosis, 470-476, Copyright (2015), with permission from Elsevier. ${ }^{93}$

broad supportive therapy would be discussed with VD. Since VD metabolism is influenced by some genetic polymorphisms that contribute to serum VD concentration, individuals probably need their own personal dose of supplementation. ${ }^{8}$ The variability between individuals in terms of VD response can be influenced by single nucleotide polymorphisms (SNPs) involved in the synthesis, binding, transport and degradation of VD.

Children with MS and the allele HLA DRB1*1501 were significantly associated with VD serum levels and relapse rate. ${ }^{9}$ Interactions between VD levels and EpsteinBarr virus (EBV) infection and HLADRB1*1501 exist, in particular relationships to antibodies to EBV antigen core 1 (anti-EBNA1). A high dose oral VD supplementation may affect the humoral immune response to the latent EBV antigen EBNA1 in RRMS, a decrease in anti-EBNA1 serum levels was observed; ${ }^{10,11}$ two to three years prior to clinical manifestation of MS, low 25(OH)D levels were registered with elevated anti-EBNA-1 IgG titers in serum.

The problem of "vitamin D, multiple sclerosis, comorbidities/therapy" has been discussed as controversial for 10 years in about 1,026 publications (PubMed search), so the following document will focus on current, practical information and will not be a presentation of comparative studies, although it will refer extensively to current literature. In a recent Canadian study, it was estimated that VD supplementation (target: $25(\mathrm{OH})-\mathrm{D}$ levels to/above $100 \mathrm{nmol} / \mathrm{L}$ ) would eliminate $40 \%$ of MS cases and reduce MS health costs (in Canadian dollars) by $\$ 1.5$ billion/ year. $^{12,13}$ The estimated cost saving effect of improving vitamin $\mathrm{D}$ status in Germany could be up to $€ 37.5$ billion/year. ${ }^{14}$

\section{Comorbidity anxiety and depression}

Depression as CM occurs in about $20-40 \%$ (up to $50 \%$ depending on definition) of PwMS during the course of the disease, anxiety in $36 \% .{ }^{15,16}$ Anglin et al were able to find a correlation between a low VD level and an increased depression rate. ${ }^{17} \mathrm{~A}$ follow-up period over 10 years on psychiatric CM was associated with progression of MSExpanded Disability Status Scale (EDSS) three points higher than without psychiatric disorders). Almost half (49\%) fulfilled the definition of "psychiatric disorder", with depression followed by anxiety and bipolar disorders being registered. ${ }^{18}$ Due to different observation durations and evaluation criteria, the mean prevalence of depression was about $30 \%$ for other investigators, $26 \%$ for anxiety and $8 \%$ for bipolar disorders. ${ }^{19-21}$ In PwMS with depression, sNfL were elevated as markers of neuroaxonal damage. This noninvasive biomarker may allow researchers to prove the efficacy of specific therapies. ${ }^{6,22}$ Serum 25 (OH)-D levels above $100 \mathrm{nmol} / \mathrm{L}$ were associated with low NfL in cerebro spinal fluid. ${ }^{23}$ Stress increases the risk of depression, relapses and new brain lesions. There are relationships between psychiatric diseases and elevated proinflammatory markers - tumor necrosis factor (TNF), interleukin-6 (IL-6). ${ }^{24}$ Empirical studies indicate a relationship between insufficient VD levels and depression, so that deficits should be compensated for. ${ }^{25}$ Quality of life is thus already impaired in the first year of the disease. ${ }^{26}$ The mechanisms for how VD could reduce depression are not clarified in detail, but the phenotypic stability hypothesis might provide an indication that VD reduces the elevated neuronal levels of intracellular $\mathrm{Ca}^{2}+$ within the inhibitory neurons that drive depression. ${ }^{27}$ VD supplementation is a possible therapeutic attempt to influence the severity of the disease, ${ }^{28}$ or to reduce the risk of recurrence. In children with MS, about one third of patients experience depression and fatigue. ${ }^{29}$ An improvement in depression was achieved in adolescents by supplementation with VD at serum levels above $30 \mathrm{ng} / \mathrm{mL} 25(\mathrm{OH}) \mathrm{D} .^{30}$

If it is necessary to prescribe an antidepressant in the phase of progressive MS (PMS), clomipramine could have an additional influence on the pathological process of MS, especially on the pronounced neurodegenerative aspect of PMS. It has been shown to affect $\mathrm{T}$ and $\mathrm{B}$ cell proliferation, reduce iron $(\mathrm{Fe})$-mediated neurotoxicity and inflammation and microglia activation, and influence axonal integrity. ${ }^{31}$

\section{Number of comorbidities related to disability and risk of relapse}

Tettey et al found evidence of greater disability and risk of relapses with increased prevalence of $\mathrm{CM}$, indicating that 
increased attention and treatment can improve prognosis. ${ }^{32}$ Persons with migraine, hyperlipidemia or a high comorbidity burden with three or more diseases showed an increased recurrence rate when observed over 2 years (14.9\% in the first and $13.2 \%$ in the second year). ${ }^{33}$ Simvastatin doses could be used for the treatment of hyperlipidemia, while allowing use of the immunomodulatory and neurotrophic effect of this drug. An already existing CM when MS was diagnosed led to a faster changes of therapy during the course of therapy due to intolerances in the first therapy. ${ }^{34} \mathrm{CM}$ were also associated with delayed diagnosis and increased mortality. ${ }^{35}$

\section{Comorbidity asthma/respiratory infections}

Asthma was detected in $12.9 \%$ of PwMS, which leads to an additional psychological burden. ${ }^{36}$ VD supplementation lowered the rate of attacks requiring treatment, especially in people managing multiple sclerosis (PwMS) with a VD level of $<25 \mathrm{nmol} / \mathrm{L}^{37}$

Similarly, VD supplementation for the prevention of acute respiratory infections in PwMS with less than 25 nmol/L achieved the greatest benefit, ${ }^{38}$ with a VD concentration of $\geq 38 \mathrm{ng} / \mathrm{mL}(\geq 95 \mathrm{nmol} / \mathrm{L})$ reducing the incidence of upper respiratory tract infections. VD is a strong inductor for antimicrobial peptides (AMPs) on mucosal surfaces and immune cells. AMPs form the "first line of defense" for invading bacteria and viruses on the mucosal surfaces of the respiratory tract. The protective effect was only achieved with daily VD supplementation. ${ }^{39}$

\section{Comorbidity osteopenia/osteoporosis}

PwMS show reduced bone mineral density (BMD) demonstrated by dual-energy X-ray absorptiometry (DEXA) with a greater risk of osteopenia, osteoporosis (low bone mass, microarchitectural deterioration of bone tissue, reduction of bone function) and fragile fractures (osteopenia: -2.5 $<\mathrm{T}$ score $<-1.0$; osteoporosis $\mathrm{T}$-score $\leq-2.5$ ). Fractures of the femoral neck were observed four times more frequently than in the normal population. ${ }^{40} \mathrm{~A}$ number of studies have reported an association between VD receptor (VDR) gene polymorphisms and BMD. ${ }^{41}$ Reduced BMD was measured in $80 \%$ of male patients after a mean disease duration of 17 years, of which $43 \%$ had osteopenia and 37\% osteoporosis; $38 \%$ osteopenia was observed in women and $44 \%$ osteoporosis. ${ }^{42}$ Simonsen et al found osteopenia or osteoporosis in $75 \%$ of MS patients. ${ }^{43}$ The need for early attention to bone metabolism is supported by the observation of low bone mass in the early stages of MS and CIS (clinically isolated syndrome). ${ }^{44}$ Among the causative mechanisms leading to the reduction of bone density, MS can be considered an inflammatory autoimmune disease per se with effects on the homeostasis of bone metabolism with destruction by osteoclasts and inhibition of bone regeneration by osteoblasts. Microarchitectural deterioration of bone tissue with increased risk of fracture has also been observed in previous therapies with antidepressants, hypnotics and anxiolytics. $^{45}$ In order to prevent fragile fractures, in PwMS it should be suggested to administer at least 4000 IU/VD, but high doses of 5000-10 000 IU/VD should also be considered in the absence of contraindications ${ }^{46}$ where DEXA measurements indicate osteopenia or osteoporosis.

The target could be a VD-serum level of 75-125 nmol/ $\mathrm{L}^{47,48}$ and supplementation should take place at least from autumn to spring. Calcium absorption in the gut is insufficient at serum VD levels $<20 \mathrm{ng} / \mathrm{mL}(<50 \mathrm{nmol} / \mathrm{L})$ and leads to secondary hyperparathyroidism. A serum concentration of $<50 \mathrm{nmol} / \mathrm{L}$ VD increases the risk of musculoskeletal complaints. ${ }^{46}$

Although there is no uniform national or international classification of VD serum levels (the accuracy of the measurement depends strongly on the method used), other cutoff values for $25(\mathrm{OH}) \mathrm{D}$ are proposed for patients where VD deficiency affects disease progression ${ }^{49}$

- Severe deficiency $\leq 50 \mathrm{nmol} / \mathrm{L}(\leq 20 \mathrm{ng} / \mathrm{mL})$

- Deficiency 52.5-72.5 nmol/L (21-29 ng/mL)

- Sufficient mirror $\geq 75 \mathrm{nmol} / \mathrm{L}(\geq 30 \mathrm{ng} / \mathrm{mL})$

Hypercalcemia as an expression of VD overdose can only be expected at $25(\mathrm{OH}) \mathrm{D} 3$ serum levels of $>375-500$ $\mathrm{nmol} / \mathrm{L}(150-200 \mathrm{ng} / \mathrm{mL}){ }^{50}$

\section{Comorbidity pain and migraines/ headaches}

Pain (headache) occurs in more than half of PwMS as a very distressing early symptom (prevalence estimated to be between 20 and 90\%) and can contribute to increased disability (increased EDSS). Headache, especially migrainetype headache, may be a symptom of incipient MS (CIS or radiologically isolated syndrome, RIS) because it is frequently observed. There is increasing evidence of a relationship between low VD levels and various chronic pain conditions. ${ }^{51-53}$ In a study with chronic pain patients, $71 \%$ showed a deficit $(<20 \mathrm{ng} / \mathrm{mL})$, in $21 \%$ showed an 
insufficient (20-30 ng/mL) VD level and only $8 \%$ showed a VD level of $>30 \mathrm{ng} / \mathrm{mL}$. Low levels were associated with a higher intensity of pain. ${ }^{54}$ Although there is no definitive knowledge on the effect of VD itself and supplementation despite numerous studies, at least one therapy attempt should be made and the serum $25(\mathrm{OH})$ levels should be titrated into the sufficient range. ${ }^{55} \mathrm{VD}$-serum levels above $75 \mathrm{nmol} / \mathrm{L}$ should be targeted, values above $125 \mathrm{nmol} / \mathrm{L}$ are unlikely to result in further benefit and values above $250 \mathrm{nmol} / \mathrm{L}$ may be considered potentially harmful. ${ }^{56,57} \mathrm{~A}$ decreased VD level also affects peripheral and parasympathetic nerve function.

The presence of VDR and vitamin-activating enzymes in the CNS as well as effects on neurotransmitters are being discussed. The main mechanism acting on the immune system, the anti-inflammatory effects, could play the largest role and patients with VD deficiency $(<30 \mathrm{nmol} / \mathrm{L})$ saw the greatest therapeutic benefit after supplementation. ${ }^{39}$

Meta-analyses have shown that there is a significant association between migraine and MS and a high prevalence (20-50\%) especially in young women with RRMS. Migraine with aura could be an indication of early manifestation of MS. Migraine is more than twice as common than among controls. ${ }^{58-61}$

A randomized, double-blind, placebo-controlled migraine prophylaxis study combining simvastatin (20 mg, twice a day) and VD (1,000 IU, twice a day) has demonstrated efficacy in preventing headache with episodic migraine. The number of days with migraine was reduced (30\% fewer migraine days). ${ }^{62}$ Frequent comorbidities include hyperlipidemia in MS, so simvastatin treatment as part of personalized medicine could significantly improve quality of life in PwMS with both conditions in the long-term. Psychiatric CM (depression and anxiety) and physical CM as well as pain are closely related and increase the suffering of PwMS. ${ }^{63}$

\section{Comorbidity and gravidity-closely related and a challenge for caregivers Optimum VD mirror as a chance for positive pregnancy progression and childbearing outcomes}

It is undisputed that treatment with DMTs achieves stability in MS, significantly improves quality of life and thus facilitates family formation. Approximately $20-30 \%$ of women with MS have children and the prevalence of pregnancy seems to have increased over the last 10 years. ${ }^{64}$ When counselling PwMS with a desire to have children, CM urgently need to be addressed to provide optimal care during pregnancy. Timely interdisciplinary cooperation between neurologists, gynecologists and internists (endocrinologists) with knowledge of MS-specific immunological alterations due to VD deficiency is desirable.

In the "real world", family planning raises many questions, such as: concerns about the health of the child, about the course of the disease with the risk of relapses, about further therapy during and after pregnancy, mode of delivery, control of CM (eg hypertension, asthma, thyroid diseases), about breastfeeding behavior and reactions in the social environment to the "pregnancy of an MS woman", etc. Preventive counseling can reduce the incidence of depression/anxiety and is a prerequisite for individual patient management.

Gravidities should be planned and recommended in a "prepregnancy consultation" to take at least 1,000-4,000 IU VD/day before conception (influence on an optimal development of the placenta) and during pregnancy. ${ }^{46}$ In case of unplanned pregnancy, VD supplementation should be started as early as possible, as starting therapy later minimizes the chance of a positive outcome.

At VD-serum values of $>80 \mathrm{nmol} / \mathrm{L}$ (at least $100 \mathrm{nmol} / \mathrm{L}$ ) fewer pregnancy-associated CMs were observed, which underscores the benefit, including the birth result. $3,65,66$

The VD metabolism of pregnant women differs drastically from that of nonpregnant women. The serum level of $1.25(\mathrm{OH})^{2} \mathrm{D}$ doubles, decoupled from calcium homeostasis, and there is no hypercalcemia or hypercalciuria. ${ }^{466}$ At no other time of life is VD status as important as in pregnancy. Not only the mother and developing fetus are influenced; the child is also influenced later on as it grows. ${ }^{66}$ A VD substitution with $4400 \mathrm{IU} /$ which occurred during pregnancy in children during the first 3 years of life showed a clear reduction in bronchial asthma or recurrent wheeze attacks. ${ }^{66}$ There is evidence that a VD deficit in pregnant women has negative effects on motor and social development in infants.

1.25-dihydroxy-VD has a direct and indirect effect on $\mathrm{T}$ cell lymphocytes and modulates the immune system in inflammatory reactions. ${ }^{67-69}$ An optimal serum VD level stabilizes the balance between the T helper lymphocytes type 1 and type 2 , a deficit is associated with more "disease-causing T cells" at the expense of regulatory T cells. ${ }^{68,69}$ MS manifestation was most frequently observed in patients born in April/May. ${ }^{68}$ As the vitamin D serum level is subject to seasonal fluctuations, the lowest relapse rate was observed in January/February, and the highest relapse rate was observed in March/April (late winter/early spring), ${ }^{70,71}$ adequate VD substitution should be performed. Immunological alterations in VD deficiency may 
occur earlier than clinical manifestations (relapses, about 2 months later).

$25(\mathrm{OH}) \mathrm{D}$ has a biological half-life of about 2 months. Miclea et al were able to show, taking into account seasonally lowered VD levels, especially in winter and early spring, that VD supplementation (increase of serum levels $25(\mathrm{OH}) \mathrm{D}$ by 51 $\mathrm{nmol} / \mathrm{L}$ ) can reduce the relapse rate by about $50 \%{ }^{71} \mathrm{VD}$ supplementation is necessary to stabilize the course of the disease during pregnancy, the postpartum period and the lactation period where no DMTs are performed. In comparison to a control group, a $30 \%$ reduction of the NfL level could be achieved. $^{72}$

\section{Promoting depression and anxiety through caesarean section}

In addition, there is sufficient evidence that severe VD deficiency $(<37.5 \mathrm{nmol} / \mathrm{L})$ represents a three-to-fourfold increased risk for a caesarean section. ${ }^{73,74}$ The associated "negative stress" promotes depression, anxiety and fatigue. ${ }^{75}$ In women without MS and elective caesarean section, a high prevalence of depressive symptoms and anxiety symptoms in late pregnancy could be verified, with depressive symptoms receding post partum faster than anxiety that persisted for longer periods after delivery. The pathophysiological explanation could be that the complex physiological and hormonal changes in vaginal delivery, with dramatic changes in the brain necessary to cope with their new situation, are not experienced by women who undergo caesarean section. Oxytocin plays a decisive role in reducing anxiety (further pathophysiology in). ${ }^{76}$

\section{Comorbidity and anemia}

$\mathrm{CM}$ anemia was observed twice as frequently in PwMS compared to controls and was also consistently associated with relapse frequency and greater disability. ${ }^{32,77,78}$ Since anemia represents an increased risk for both mother and child, VD supplementation should be used. VD reduces pro-inflammatory cytokines and suppresses hepcidin mRNA transcription, meaning it may increase the availability of iron, and there is also evidence that VD may support erythropoiesis. Through these potential mechanisms of action, VD can prevent or improve anemia, in particular anemia of inflammation (pathophysiological mechanisms in). ${ }^{79}$

\section{Thrombocytopenia}

Thrombocytopenia in pregnant women without MS (platelet counts $<150 \times 10(9) / \mathrm{L})$ were observed to be $6.6-11.6 \%$ in the third trimester. ${ }^{80,81}$ Moreover, epidemiological studies have shown a prevalence of ITP (immune thrombocytopenia) in MS patients 25 times higher than in the general population.82,83 Gestational thrombocytopenia with $5-8 \%$ of all pregnant women (without MS) is the most frequent thrombocytopenia with $2 / 3$ and is mild, asymptomatic without evidence of thrombocytopenia in the anamnesis and without increased risk for mother and child. The thrombocyte values are mostly between 130 and $150 \times 10(9) / \mathrm{L}$, but almost always $>70 \times 10(9) /$ $\mathrm{L}^{84,85}$ and return to normal within 2 weeks postpartum.

A primary ITP with platelet counts $<100 \times 10(9)$ is observed in $1-4 \%$ of gravidity, predominantly in the first and early second trimester. In ITP, which is caused by platelet antibodies (IgG class AK against glycoprotein complexes of the platelet membrane), AK can lead to thrombocytopenia in newborns due to diaplacental crossing. Therefore, such patients require special care during delivery and interdisciplinary monitoring of the newborn. ${ }^{85}$

Differential diagnosis of alemtuzumab-induced secondary thrombocytopenia in MS therapy is difficult because the determination of thrombocyte-AK in thrombocytopenia is technically complex, only available in specialized laboratories and interpretation is problematic due to different test systems. Alemtuzumab, a humanized monoclonal antibody against the glycoprotein CD52, causes depletion and repopulation of $\mathrm{B}$ lymphocytes and $\mathrm{T}$ lymphocytes, leading to prolonged changes in the adaptive immune system. It is used in patients with relapsing-remitting MS with (highly) active course. An extended differential diagnosis of thrombocytopenia in pregnancy can be found in the overview by Gernsheimer et al as well as Bergmann and Rath. ${ }^{81,85}$ From a prophylactic point of view, an optimal $25(\mathrm{OH}) \mathrm{D}$ serum level should be achieved to avoid ITP. At very low VD values the ITP cases also showed a lower number of thrombocytes. ${ }^{86-89}$

\section{Maximizing therapeutic opportunities to delay the transition from RRMS to secundary progressive multiple sclerosis (SPMS)}

If anxiety is defined as "a feeling of worry, nervousness, or discomfort about something with an uncertain outcome," this applies unreservedly to PwMS. The anxiety of recurrences with the risk of being "wheelchairbound" must also be reduced by using effective relapse therapy and all current therapeutic findings to stop further neurodegeneration. The permanent "negative stress" (fear of increasing disability) increases the 
manifestation of depression, anxiety and fatigue. ${ }^{75}$ If $36-54 \%$ of PwMS are confronted with anxiety and studies have clearly shown that anxiety (and depression) is also associated with cognitive impairment, ${ }^{90}$ therapy counseling "in an open and honest partnership" with our PwMS is a conditio sine qua non. ${ }^{91}$ The questionable association between "depression" and "DMT therapy" was investigated by Gasim et al (side effects of DMT with regard to psychiatric comorbidities in natalizumab, dimethylfumarate, teriflunomide and alemtuzumab). ${ }^{92}$ DMTs have not been associated with an increased risk of adverse psychiatric effects and some may even reduce the incidence of depressive symptoms. This may reflect either a positive direct effect of immune modulation or an indirect effect resulting from a positive influence on disease activity or course. ${ }^{92}$ PwMS with progressive course of MS also showed an increase in pain and disability. ${ }^{93}$ To improve the well-being of PwMS, the latest research findings should quickly be put into practice as one way to reduce anxiety and depressive states. Giovannoni advocates for motivating PwMS as an effective disease-modifying therapy, albeit with side effects, in order to limit cognitive deficits. ${ }^{91}$ Early cognitive impairment combined with progressive brain volume loss can only be stopped if the available therapeutic drugs are used. Since cognitive dysfunctions affect about $40-70 \%$ of PwMS over the course of their lives, can have a progressive course and since there is no established treatment, higher VD values should be sought, as Cortese et al at the 34th Congress of ECTRIMS 2018 demonstrated by a study that early VD supplementation could be neuroprotective. ${ }^{94}$ Highdose VD supplementation (4,000 IU/day) improved nonverbal (visual) memory after 18 weeks, especially in those individuals where $25(\mathrm{OH}) \mathrm{D}$ levels were $<75$ nmol/L. ${ }^{95}$

It is essential to slow down the transition to SPMS if CMs such as anxiety, depression and personality changes, are to be reduced. In a survey, $80 \%$ of PwMS reported that neurologists and other caregivers never talked to them about "brain volume loss" or "brain atrophy". 77\% of MS patients would be more open to further treatment if they were informed about this "creeping dementia". 91

Although SPMS is associated with severe, irreversible disabilities, the medical literature focuses on the highly effective anti-inflammatory therapy of RRMS. ${ }^{32}$ Fifty percent of RRMS patients experience the transition to SPMS without therapy in about 10 years and $90 \%$ in $20-25$ years. DMTs can prolong these times. However, about half of patients with SPMS do not receive DMTs or the drug was not sufficiently efficient. ${ }^{96}$ Antiinflammatory treatment loses effectiveness in the late stage of RRMS and early progressive stage of SPMS and neurodegeneration predominates.

Such neurodegeneration affects the damaged brain and spinal cord, where the functional reserve capacity is exhausted, leading to a progression of disability with all its facets. Since the drugs available today can only prevent or curb progression to a limited extent, priority must be given to preventing the conversion of RRMS to SPMS. Whether the progression of neurodegeneration can be influenced by siponimod or simvastatin ${ }^{97}$ is currently being investigated for siponimod in the EXPAND study (NCT01665144). ${ }^{98}$ Siponimod is a second generation selective S1P1 and S1P5 receptor modulator and a further development of fingolimod. Evaluations to date have shown a positive oral effect at a daily dose of once $2 \mathrm{mg}$. Siponimod reduced the risk of disability. ${ }^{98}$ The US Food and Drug Administration (FDA) has approved siponimod tablets 2019 to treat adults with relapsing forms of MS (RRMS), including CIS, and active secondary progressive disease. The manufacturer has also applied to the European Medicines Agency (EMA) for 2019 approval.

Siponimod reduces sNfL levels in the blood of SPMS. The sNfL blood levels are elevated in RRMS and SPMS and reflect neuronal damage. ${ }^{6}$ Patients in a progressive stage who have a clinical manifestation with cognitive impairment and neuropsychiatric dysfunction may experience dramatic effects on their quality of life. Evidence that simvastatin (two times $40 \mathrm{mg} /$ day), with its immunomodulatory and neurotrophic properties, ${ }^{99}$ has a positive effect on frontal lobe function and improves physical quality of life and may expand the individual therapeutic repertoire in SPMS. ${ }^{100-102}$ This high daily dose of simvastin reduced annual brain atrophy by $42 \%{ }^{102}$

Muris et al were able to demonstrate that low serum vitamin D levels (25(OH)D) lead to early conversion to SPMS. ${ }^{103}$ In a national study in the Netherlands, a followup study with a minimum period of 3 years was conducted with $554 \mathrm{MS}$ patients with a serum baseline of $25(\mathrm{OH}) \mathrm{D}$ and an EDSS. This national study was carried out in 2 centers of the Netherlands located at 51 degrees north latitude.

Vitamin D status is lower in SPMS patients than in RRMS. SPMS patient with a short RRMS duration also have low diagnostic 25(OH)D levels.

VD status is not only associated with the risk and onset of MS, but also influences the degree of disease activity 
and progression. A $25 \mathrm{nmol} / \mathrm{L}$ higher VD level was associated with a $15 \%$ lower risk for later new T2 lesions in MRI and about $1 / 3$ reduction for the risk of new gadolinium (Gd) enriching lesions. ${ }^{104}$ The VD level is key for therapeutic success. A $50 \mathrm{nmol} / \mathrm{L}$ higher serum-25(OH)D level was associated with a $31 \%$ lower rate of new lesions. ${ }^{105} \mathrm{VD}$ values $\geq 100 \mathrm{nmol} / \mathrm{L}$ had a $47 \%$ lower rate of new T2 lesions and new Gd-enriching lesions compared to patients who had a VD level of 50-75 nmol/L. ${ }^{105} \mathrm{VD}$ values $\geq 100 \mathrm{nmol} / \mathrm{L}$ had a $47 \%$ lower rate of new $\mathrm{T} 2$ lesions and new Gd-enriching lesions compared to patients who had a VD level of $50-75 \mathrm{nmol} / \mathrm{L}$. VD values $\geq 100$ $\mathrm{nmol} / \mathrm{L}$ had a $47 \%$ lower rate of new T2 lesions and new Gd-enriching lesions compared to patients who had a VD level of 50-75 nmol/L. ${ }^{105} \mathrm{VD}$ levels also showed an inverse correlation to grey matter volume loss, with 25 $\mathrm{nmol} / \mathrm{L}$ higher 25(OH)D values associated with $7.8 \mathrm{~mL}$ higher grey matter volume (overview at). ${ }^{106}$ There is evidence that insufficient $25(\mathrm{OH}) \mathrm{D}$ levels are associated with cognitive impairment and VD levels above $100 \mathrm{nmol} / \mathrm{L}$ improve executive function. ${ }^{107}$ Since cognitive deficits have a high relevance in the everyday and professional lives of PwMS, even the slightest therapeutic effects should be taken advantage of.

\section{Sun exposure, latitude gradient and vitamin D levels}

The ultraviolet radiation (UVR) and the dietary intake of vitamin D (eg fatty fish, fortified foods) are decisive for the personal vitamin D level. A greater distance from the equator (higher latitudes) and the number of months with little sunshine increases the vitamin D deficiency. Other factors such as race, ethnicity (Blacks, Hispanics, Whites), genetic susceptibility, climatic variation, sun-seeking behaviors and clothing habits play a role. ${ }^{108}$ There are differences between White patients, Blacks or Hispanics of a Mexican background. There is also evidence that UVR itself has immunological effects independent of the vitamin metabolic pathway ${ }^{109}$ Sun exposure appears to be an important factor in reducing the risk of MS in all ethnic groups, especially in Blacks and Hispanics. A dark skin tone does not weaken the immunological effect. ${ }^{110}$ Higher lifetime UVR exposure was associated with a lower risk of MS independent of serum 25(OH) D levels in Blacks and Whites with a similar magnitude of effect that did not reach statistical significance in Hispanics. Higher serum 25(OH)D levels were associated with a lower risk of MS only in Whites. ${ }^{111}$
Rito et al investigated vitamin D and disability in RRMS in PwMS with Hispanics and Mexican background. No correlation was found between vitamin D levels and EDSS score, annual relapse rate (ARR), progression index (PI) or duration of disease. The limitation of this study is that the VD levels in summer were determined and the mean vitamin $\mathrm{D}$ level for PwMS was insufficient $(22.3 \mathrm{ng} / \mathrm{mL}){ }^{112}$

\section{Influence of parental MS with comorbidities on the life path of children}

The course of the disease also has a serious impact on the lives of children whose parents have MS, even late into adulthood. The social impact of MS is rarely discussed. ${ }^{91}$ It is undisputed that $\mathrm{CM}$ additionally burden family life. The children are not only confronted with the problem of caring for the sick parent, they have to hide their feelings and desires. Fear and depression as well as shame are problems that have to be dealt with and can lead to a lack of openness. A greater disability of the MS parent (especially the mother) through mental and physical CM has an impact on children's health development. ${ }^{113}$ At the age of 30 , they were less often employed, and at the age of 30-40 they received a disability pension more often and their annual gross income at work was lower than that of their peers. ${ }^{114}$

\section{Future aspects of vitamin D supplementation}

Carlberg et al developed the concept of the "personal VD response index" and were able to classify persons receiving a VD supplementation as high, medium and low respondents. The "personal VD response index" describes the effectiveness of the molecular response to supplementation with VD. For example, persons with a low VD response index should aim for a high VD status in order to derive maximum benefit from VD's protective role. This suggests that the dose of daily VD supplementation should be adjusted to the VD response index of the individual and not only to VD status. ${ }^{115}$ Measuring "vitamin D sensitive molecular parameters" would facilitate the controversial discussion about the recommended VD dose, although the determination in practice is still in the distant future.

\section{Monitoring of the safety of (long- term) VD therapy}

For all MS patients, including during pregnancy, multiple benefits can be expected from a VD supplementation of 
Table 4 Positive effects of an optimal vitamin D status (target at least 25(OH)-D serum levels of $40-60 \mathrm{ng} / \mathrm{mL}$ [100-150 nmol/L]) on comorbidities, pregnancy and disease progression in MS

\begin{tabular}{|c|c|}
\hline Depression/anxiety & $25,28-30,142$ \\
\hline Asthma & $37-39$ \\
\hline Osteoporosis & $46-48$ \\
\hline Pain, migraines/headache & $51-6 \mid$ \\
\hline Neurocognitive functions & $49,94,95,132$ \\
\hline Cardiovascular diseases (VD levels between 40 and $100 \mathrm{nmol} / \mathrm{L}$ ) & 129 \\
\hline Anemia (haemoglobin $<12 \mathrm{~g} / \mathrm{dL}$ for women, $<13 \mathrm{~g} / \mathrm{dL}$ for men) & $78,79,86$ \\
\hline $\begin{array}{l}\text { Pregnancy (minimum intake of VD 4,000 IU before conception and throughout pregnancy, (minimization of preterm births, } \\
\text { preeclampsia, gestational diabetes, positive influence on brain development, lung maturation and function of the fetus, postnatal } \\
\text { asthma prevention). }\end{array}$ & 65,127 \\
\hline $\begin{array}{l}\text { Course of multiple sclerosis }{ }^{143} \text { reduction of risk of relapse, reduction of new T2 lesions and increase in size, reduction of } \\
\text { gadolinium-enriching lesions, reduction of brain atrophy, reduction of transition from CIS to definitive MS. }{ }^{30} \mathrm{sNfL} \text { levels as } \\
\text { markers of axonal degeneration reduced by approximately } 30 \% \text { in PWMS [without DMTs] }\end{array}$ & 72 \\
\hline
\end{tabular}

Abbreviations: VD, vitamin D; CIS, clinically isolated syndrome; sNfL, serum neurofilament light chains; DMT; disease modifying treatment.

2000-5000 IU/for all forms of MS from a practical point of view, according to the current state of knowledge (Table 4). Before starting supplementation, it is useful to determine the baseline values of $25(\mathrm{OH}) \mathrm{D}$ and serum $\mathrm{Ca}$ in order to estimate the "saturation dose", including seasonal influences or obesity (requires about 2.5 times higher dose) in advance. An additional intake of calcium should be avoided at all costs. VD serum levels of at least 30 (40)-60 ng/mL (75[100]-150 nmol/L) are desirable. A control should be performed after about 3 months of treatment, with laboratory chemical monitoring dates varying depending on the individual baseline situation (initial VD serum level, VD dose level). There is little risk of hypercalcemia or other side effects with moderate add-on treatment ${ }^{116}$ even with daily intake of VD up to $10,000 \mathrm{IU} /$ day (46). Although it is known that VD increases the absorption of calcium from the gut, this effect is generally subject to physiological regulation.

At serum $\mathrm{Ca}$ levels above $80 \mathrm{nmol} / \mathrm{L}$, further intestinal $\mathrm{Ca}$ absorption is not increased. There is a balance between net $\mathrm{Ca}$ absorption from the intestine and calcium excretion in the kidney. An excessive production of the active 1.25 $(\mathrm{OH}) \mathrm{D} 3$ results in an adequate production of the catabolic enzyme 24-hydroxylase (CYP24A1), largely avoiding VD toxicity. ${ }^{117}$ A possible (theoretical) mechanism of VD toxicity could be based on changes in the metabolic pathway by displacement of $1.25(\mathrm{OH}) \mathrm{D}$ from its binding protein (DBP). If the DBP binding capacity is exceeded, eg caused by $25(\mathrm{OH}) \mathrm{D}$ itself, hypercalcemia could occur. ${ }^{46}$

In long-term therapy with high VD doses, it is mainly the $25(\mathrm{OH}) \mathrm{D}$ serum level, but also the serum calcium and phosphate value, that must be determined in order to detect VD overdose/intoxication in good time. In very rare cases an imbalance of $\mathrm{Ca}$ /phospor homeostasis can occur without VD hypervitaminosis and in rare cases extremely high VD levels cannot cause hypercalcemia. Because VD intoxication without VD hypervitaminosis has been verified in anecdotal reports, a determination of Ca excretion in 24-hour collecting urine (hypercalciuria?) can optionally be performed to confirm this. ${ }^{118}$ VD toxicity would be indicated by serum Ca above $2.75 \mathrm{mmol} / \mathrm{L}$. The molar calcium/creatinine ratio in urine $(>1)$ can also be used for identification. ${ }^{119}$ The determination of parathyroid hormone (PTH) is more complex, whereby the $25(\mathrm{OH}) \mathrm{D}$ serum level is inversely associated with the PTH level. Elevated PTH serum levels were found at $40 \%$ (adults) with $25(\mathrm{OH})$-values $\leq 50 \mathrm{nmol} / \mathrm{L}$, while at $\leq 25$ nmol/51\% the PTH level was elevated "biochemical hyperparathyroidism". ${ }^{120}$

The period of monitoring should depend on the daily VD dose level, the season (summer/winter) and the interim control results (laboratory values), with a minimum of 6 or 12 months of controls required.

Based on the patient's medical history, it should be determined whether PwMS should carry out supplementation with high-dose VD up to $60,000 \mathrm{IU} /$ the ("Coimbra protocol") as additional therapy with VD doses. This treatment protocol requires tight control of serum $\mathrm{Ca}$ and PTH levels and such extreme dosing should only be performed as part of a study. The PTH level should be close to the lower limit of the normal range, too low a $\mathrm{PTH}$ level would indicate a toxic effect of VD. In addition, a low-calcium diet without dairy products and a daily intake of $2.5 \mathrm{~L}$ of liquid is required to avoid kidney damage. ${ }^{121}$ 
Another possible cause of VD hypervitaminosis may be low activity of the catabolic enzyme 24-hydroxylase (CYP24A1). Mutations in the CYP24A1 gene are associated with a partial or total loss of 24-hydroxylase activity, which may result in hypercalcemia. ${ }^{117}$ In addition, nontoxic VD levels $(<375 \mathrm{nmol} / \mathrm{L})$ or nonhypervitaminotic levels $(<250$ $\mathrm{nmol} / \mathrm{L}$ ) have shown very rare cases of intoxication.

The threshold for toxic symptoms is generally a plasma level of about $750 \mathrm{nmol} / \mathrm{L}(300 \mathrm{ng} / \mathrm{mL})$ 25(OH) D3. Considering this value and considering that the generally accepted upper limit of the normal range has been established as $250 \mathrm{nmol} / \mathrm{L}(100 \mathrm{ng} / \mathrm{mL})$, there is still a wide margin of safety upwards, as values above this were not associated with toxicity (Tables 5 and 6 ). ${ }^{122}$

\section{How do PwMS use vitamin D supplementation?}

In an international survey (Internet platform) of over 2,000 PwMS more than 4 years ago, more than $81.8 \%$ took VD, with the calculated daily dose lying between 2000 and $5000 \mathrm{IU} /$ day, while $18.2 \%$ did not supplement VD. ${ }^{123}$ The "VD problem" will have to play a key role in improving the quality of life.

\section{Neurorehabilitation and comorbidities}

$\mathrm{CM}$ could become a central problem in rehabilitation. PwMS with CM showed more severe changes in MRI as an indication of increased neurodegeneration and demyelination. Anxiety, depression, hypertension, migraine and hyperlipidemia were the most common concomitant diseases in 885 participants observed over 2 years. ${ }^{32}$ Therapeutic observation of $\mathrm{CM}$ could help to minimize the devastating effects of the disease. During a routine clinic visit within one year, CM was registered between 6 and 29\% (Table 3) of patients. There may be a temporal discrepancy for when current clinical symptoms manifest (clinical-radiological paradox). This "time lag" could be explained by an existing functional reserve and possible plasticity mechanisms. When these compensating mechanisms are exhausted, however, a progressive clinical stage will very quickly set in. ${ }^{124}$ The observation of (autoimmune) $\mathrm{CM}$ as an indication of a possible clinical and radiological progression of MS and the therapeutic attempt to stop this progression could impact patient quality of life. During rehabilitation, it is possible to discuss the possibilities of intervention with PwMS and to set the course for further therapies at home. These intentions will be pursued all the more frequently when it is realized that MS patients with migraine, hyperlipidemia and/or high stress with three or more $\mathrm{CM}$ have a higher rate of deterioration. ${ }^{32}$ Since vascular $\mathrm{CM}$ are associated with faster disability progression and simvastatin affects vascular function and has immunomodulatory and neurotrophic effects, statin therapy may be a possible extension of the therapeutic arsenal. The potential for side-effects is known from years of use in lipid therapy.

As the prevalence of cognitive deficits is observed to be about $34-65 \%$, the National MS Society, USA has asked experts (clinicians, rehabilitation physicians, researchers and PwMS) to develop recommendations for cognitive screening and cognitive impairment management in conjunction with existing $\mathrm{CM}$ to improve the quality of life of these groups of people in education, at work or at home. The Consortium of Multiple Sclerosis Centers and the International Multiple Sclerosis Cognition Society support the extensive concrete recommendations

Table 6 Conversions for laboratory values of different units

Conversions: 25 -hydroxyvitamin D-level [25(OH)D]: $\mathrm{ng} / \mathrm{mL} x$

$2.5=\mathrm{nmol} / \mathrm{L}$

Equivalences: I $\mathrm{ng} / \mathrm{mL}=2,5 \mathrm{nmol} / \mathrm{L}$

Vitamin D conversions: I $\mu \mathrm{g}$ vitamin $\mathrm{D}=40 \mathrm{IU}, \mathrm{IIU}=0.025 \mu \mathrm{g}$

Table 5 Orienting 25(OH)D levels for the practice

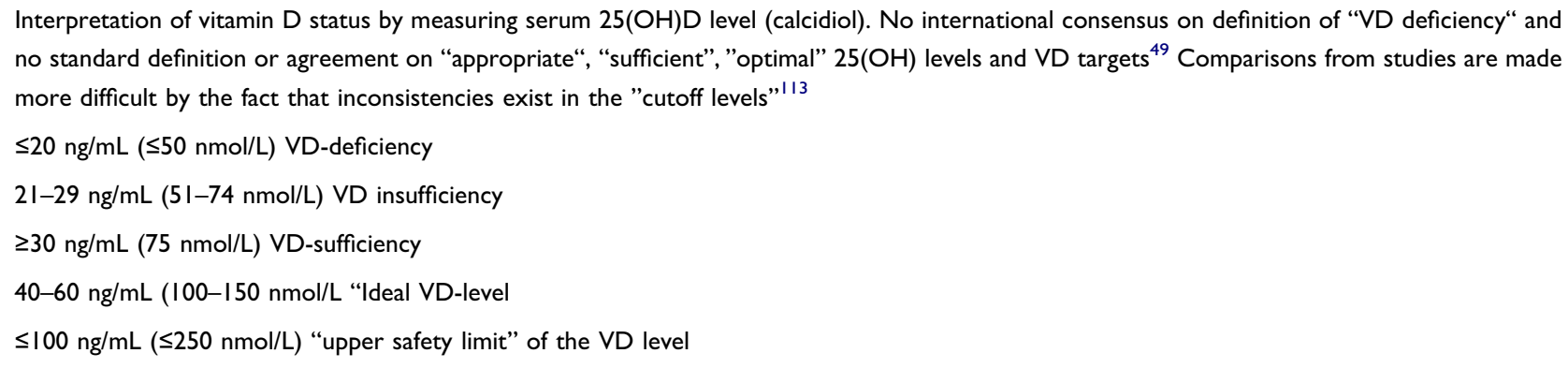

Abbreviation: VD, vitamin $\mathrm{D}$. 
issued and call for increased awareness and education of physicians and patients about the prevalence, effects and appropriate management of cognitive symptoms (detailed recommendations in). ${ }^{125}$

\section{Relationship of comorbidity to disease activation}

The occurrence of mood swings, anxiety and depression can no longer be seen as a consequence of disease awareness and disability, but as something more complex.

Rossi et al found a correlation of mood changes with intrathecal inflammation and activities in cerebral MRI. The measurement of cytokines in cerebrospinal fluid revealed an association of IL-2 with anxiety and IL-1ß/ TNF- $\alpha$ with depression. PwMS with active disease had higher anxiety and depression values in psychiatric examinations (Beck Depressions Inventory, BDI; State/Trait Anxiety Inventory, STAI). In a small group of 20 patients with active MS, 5-day methylprednisolone pulse therapy (1,000 mg/day) was performed and anxiety levels improved. This study suggests that inflammation itself may be responsible for mood swings and that this finding must be used to evaluate anxiety as an early indication of a subclinical relapse in RRMS before clinically abnormal symptoms occur. ${ }^{126}$

\section{Conclusion for practice}

According to the current state of knowledge, VD supplementation should be carried out with the aim of achieving the following goals:

- Correction of VD insufficiency detectable in the vast majority of MS patients (minimum target: VD serum levels $30-60 \mathrm{ng} / \mathrm{mL}(75-150 \mathrm{nmol} / \mathrm{L})$. Safety in longterm VD supplementation by controlling serum VD, Ca and phosphate levels

- Prophylaxis against infections

- Prevention of osteopenia and osteoporosis as well as consecutive fragile fractures

- Reduction of comorbidity and slowing of disease progression

"The practice of medicine remains more an art than a science" (Gavin Giovannoni, 2017) ${ }^{91}$

"A gestational dose of vitamin D per day keeps the MS doctor away " (Ruth Ann Marrie, Martin Daumer, $2017)^{130}$

\section{Disclosure}

The author reports no conflict of interest in this work.

\section{References}

1. Holstiege J, Steffen A, Goffrier B, Bätzing J. [Epidemiology of multiple sclerosis a population-based, Germany-wide study] Zentralinstitut für die kassenärztliche Versorgung in Deutschland (Zi). Versorgungsatlas-Bericht Nr. 17/09. Berlin. 2017. German. doi:10.20364/VA-17.09

2. Capkun G, Dahlke F, Lahoz R, et al.Mortality and comorbidities in patients with multiple sclerosis compared with a population without multiple sclerosis: an observational study using the US department of defense administrative claims database. Mult Scler Relat Disord. 2015;(4):546-554. doi:10.1016/j.msard.2015.08.005

3. Marrie RA. Comorbidity in multiple sclerosis: implications for patient care. Nat Rev Neurol. 2017;13(6):375-382. doi:10.1038/ nrneurol.2017.33

4. Montalban X, Gold R, Thompson AJ, et al. ECTRIMS/EAN guideline on the pharmacological treatment of people with multiple sclerosis. Mult Scler. 2018;24:1-25. doi:10.1177/1352458517751049

5. Lo LMP, Taylor B, van der Mai I. The prevalence of comorbidities before and after the onset of multiple sclerosis compared to the general population. ECTRIMS Online Lib. 2018;11:228575.P732.

6. Kuhle J, Nourbakhsh B, Grant D, et al. Serum neurofilament is associated with progression of brain atrophy and disability in early MS. Neurology. 2017;88:1-6. doi:10.1212/WNL.0000000000003653

7. Gotte M, Mayer C, Huebner J. Use of complementary and alternative medicine in patients with multiple sclerosis in Germany. Complement Ther Med. 2018;36:113-117. doi:10.1016/j.ctim.2017.12.006

8. Harroud A, Richards JB. Mendelian randomization in multiple sclerosis: a causal role for vitamin d and obesity? Mult Scler. 2018;24(1):80-85. doi:10.1177/1352458517737373

9. Graves JS, Barcellos LF, Shao X, et al. Genetic predictors of relapse rate in pediatric MS. Mult Scler. 2016;22:1528-1535. doi: $10.1177 / 1352458515624269$

10. Rosjo E, Lossius A, Abdelmagid N, et al. Effect of high-dose vitamin D3 supplementation on antibody responses against Epstein-Barr virus in relapsing-remitting multiple sclerosis. Mult Scler. 2017;23(3):395-402. doi:10.1177/1352458516654310

11. Rolf L, Muris AH, Mathias A, et al. Exploring the effect of vitamin D3 supplementation on the anti-EBV antibody response in relapsing-remitting multiple sclerosis. Mult Scler. 2017. [Epub ahead of print]. doi: $10.1177 / 1352458517722646$

12. Ascherio A, Munger KL. Epidemiology of multiple sclerosis: from risk factors to prevention-an update. Semin Neurol. 2016;36 (2):103-114. doi:10.1055/s-0036-1579693

13. Grant WB, Whiting SJ, Schwalfenberg GK, et al. Estimated economic benefit of increasing 25-hydroxyvitamin D concentrations of Canadians to or above $100 \mathrm{nmol} / 1$. Dermatoendocrinol. 2016;8: e1248324. doi:10.1080/19381980.2016.1248324

14. Zittermann A. The estimated benefits of vitamin D for Germany. Mol Nutr Food Res. 2010;54(8):1164-1171. doi:10.1002/mnfr.200900494

15. Jetté N, Amoozegar F, Patten SB. Depression in epilepsy, migraine, and multiple sclerosis. Neurol Clin Pract. 2017;7(2):118-127. doi: 10.1212/CPJ.0000000000000349

16. Marrie RA, Hanwell H. General health issues in multiple sclerosis: comorbidities, secondary conditions, and health behaviors. Mult Scler. 2013;19(4):1046-1057.

17. Anglin RE, Samaan Z, Walter SD, McDonald SD. Vitamin D deficiency and depression in adults: systematic review and meta-analysis. BJPsych. 2013;202(2):100-107. doi:10.1192/bjp.bp.111.106666

18. McKay KA. Association between psychiatric comorbidity and disability progression of multiple sclerosis. Ectrims. 2017;26;2017:202458. 
19. Minden SL, Feinstein A, Kalb RC, et al. Evidence-based guideline: assessment and management of psychiatric disorders in individuals with MS. Neurology. 2014;82:174-181. doi:10.1212/ WNL.0000000000000013

20. Marrie RA, Reingold S, Cohen J, et al. The incidence and prevalence of psychiatric disorders in multiple sclerosis: a systematic review. Mult Scler. 2015;21(3):305-317. doi:10.1177/1352458514564487

21. Kalron A, Aloni R. Contrasting relationship between depression, quantitative gait characteristics and self-report walking difficulties in people with multiple sclerosis. Mult Scler Rel Dis. 2018;19:1-5. doi:10.1016/j.msard.2017.10.012

22. Piehl F, Kockum I, Khademi M, et al. Plasma neurofilament light chain levels in patients with MS switching from injectable therapies to fingolimod. Mult Scler. 2018;24(8):1046-1054.

23. Sandberg L, Bistro M, Salzer J, et al. Vitamin D and axonal injury in multiple sclerosis. Mult Scler. 2016;22:1027-1031. doi:10.1177/ 1352458515606986

24. Dowlati Y, Herrmann N, Swardfager W et al. A meta-analysis of cytokines in major depression. Biol Psychiatry. 2010;67:446-457. doi:10.1016/j.biopsych.2009.09.033

25. Parker GB, Brotchie H, Graham RK. Vitamin D and depression. $J$ Affect Disord. 2017;208:56-61. doi:10.1016/j.jad.2016.08.082

26. Nourbakhsh B, Julian L, Waubant E. Fatiuge and depression predict quality of life in patients with early multiple sclerosis: a longitudinal study. Eur J Neurol. 2016;23(9):1482-1486. DOI:10.1111/ene.13102.

27. Berridge MJ. Vitamin D and depression: cellular and regulatory mechanisms. Pharmacol Rev. 2017;69(2):80-92. doi:10.1124/pr.116.013227

28. Wong SH, Chjin KY, Ima-Nirwana S. Vitamin D and depression: the evidence from an indirect clue to treatment strategy. Curr Drug Targets. 2017; (Epub ahead of print) doi:10.2174/ 1389450118666170913161030

29. Parrish JB, Weinstock-Guttman B, Smerbeck A, et al. Fatigue and depression in children with demyelinating disorders. J Child Neurol. 2012;28(6):713-718. doi:10.1177/0883073812450750

30. Högberg G, Gustafsson SA, Hällström T, et al. Depressed adolescents in a case-series were low in vitamin D and depression was ameliorated by vitamin D supplementation. Acta Paediatr. 2012;101:779-783. doi:10.1111/j.1651-2227.2012.02655.x

31. Faissner S, Mishra M, Kaushik DK, et al. Systematic screening of generic drugs for progressive multiple sclerosis identifies clomipramine as a promising therapeutic. Nat Commun. 2017;8. doi:10.1038/s41467-017-02119-6

32. Tettey P, Siejka D, Simpson S Jr, et al. Frequency of comorbidities and their association with clinical disability and relapse in multiple sclerosis. Neuroepidemiology. 2016;46(2):106-113. doi:10.1159/000442203

33. Kowalec K, McKay KA, Patten SB, et al. Comorbidity increases the risk of relapse in multiple sclerosis: a prospective study. Neurology. 2017 [Epub ahead of print].

34. Laroni A, Signori A, Maniscalco GT, et al. Assessing association of comorbidities with treatment choice and persistence in MS. Neurology. 2017. [(Published online before print)]. doi:10.1212/ WNL.0000000000004686

35. Thormann A, Soelberg Sorensen P, Koch-Henriksen N, et al. Comorbidity in multiple sclerosis is associated with diagnostic delays and increased mortality. Neurology. 2017;89(16):16681675. doi:10.1212/WNL.0000000000004508

36. Manouchehrinia A, Edwards LJ, Roshanisefat H, et al. Multiple sclerosis course and clinical outcomes in patients with comorbid asthma: a survey study. BMJ Open. 2015;5(5):e007806. doi:10.1136/bmjopen-2015-007806

37. Jolliffe DA, Greenberg L, Hooper RL, et al. Vitamin D supplementation to prevent asthma exacerbations. A systematic review and meta-analysis of individual participant data. Lancet Respir Med. 2017. doi:10.1016/S2213-2600(17)30306-5
38. Martineau AR, Jolliffe DA, Hooper RL, et al. Vitamin D supplementation to prevent acute respiratory tract infections: systematic review and meta-analysis of individual participant data. BMJ. 2017:356 i6583. Published 15 February 2017. DOI:10.1136/bmj.i6583

39. Helde-Frankling M, Björkhem-Bergman L. Vitamin D in Pain Management. Int J Mol Sci. 2017;18:2170-2179. doi:10.3390/ ijms 18102170

40. Bazelier MT, van TP S, Uitdehaag BMJ, et al. Risk of fractures in patients with multiple sclerosis. Neurology. 2012;78(24):19671973. doi:10.1212/WNL.0b013e318259e0ff

41. Wu J, Shang DE, Yang S, et al. Assoziation zwischen dem Vitamin-D-Rezeptor-Genpolymorphismus und Osteoporose. Biomed Rep. 2016;5(2):233-236. doi:10.3892/br.2016.697

42. Marrie RA, Cutter G, Tyry T, et al. A cross-sectional study of bone health in multiple sclerosis. Neurology. 2009;73:1394-1398. doi:10.1212/WNL.0b013e3181beece8

43. Simonsen SC, Celius EG, Brunborn C, et al. Bone mineral density in patients with multiple sclerosis, hereditary ataxia or hereditary spastic paraplegia after at least 10 years of disease- a case control study. BMC Neurol. 2016;16:252.

44. Moen SM, Celius EG, Sandvik L, et al. Bone turnover and metabolism in patients with early multiple sclerosis and prevalent bone mass deficit: a populations-based case-control study. PLoS. 2012;7 (9):e45703. doi:10.1371/journal.pone.0045703

45. Bazelier MT, van Staa TP, Uitdehaag BM, et al. Risk of fractures in patients with multiple sclerosis. A population-based study examining the risk of fracture in patients with MS, leading to the development of a novel method of estimating fracture risk in this population. Neurology. 2012;78(24):1967-1973. doi:10.1212/ WNL.0b013e318259e0ff

46. Dobson R, Cock HR, Brex P, Giovannoni G. Vitamin D supplementation. Pract Neurol. 2018;18(1):35-42.

47. Binks S, Dobson R. Risk factors, epidemiology and treatment strategies for metabolic bone disease in patients with neurological disease. Curr Osteoporos Rep. 2016.

48. Holmoy T, Torkildsen O, Myhr K-M, et al. Vitamin D supplementation and monitoring in multiple sclerosis: who, when and wherefore. Acta Neurol Scand Suppl. 2012;195:63-69. doi:10.1111/ane.12028

49. Holick MF, Binkley NC, Bischoff-Ferrari HA, et al. Evaluation, treatment, and prevention of vitamin D deficiency: an endocrine society clinical practice guideline. J Clin Endocrinol Metab. 2011;96:1911-1930. doi:10.1210/jc.2011-0385

50. Kramer J, Diehl A, Lehnert H. Epidemiological study on the dimension of vitamin D deficiency in North Germany. Dtsch Med Wochenschr. 2014;139:470-475. doi:10.1055/s-0033-1360073

51. Shipton EE, Shipton EA. Vitamin D deficiency and pain: clinical evidence of low levels of vitamin D and supplementation on chronic pain states. Pain Ther. 2015;4:67-87. doi:10.1007/ s40122-015-0036-8

52. Gaikwad M, Vanlint S, Moseley GL. Factors associated with vitamin D testing, deficiency, intake, and supplementation in patients with chronic pain. J Diet Suppl. 2017; (Epub ahead of print). doi:10.1080/19390211.2017.1375060

53. Amerongen van BM, Feron F. Effect of high-dose vitamin D3 intake on ambulation, muscular pain and bone mineral density in a women with multiple sclerosis: a 10-year longitudinal case report. Int J Mol Sci. 2012;13(10):13416-13483. doi:10.3390/ijms131013461

54. Von Kanel R, Muller-Hartmannsgruber V, Kokinogenis G, et al. Vitamin D and central hypersensitivity in patients with chronic pain. Pain Med. 2014. doi:10.1111/pme.12454

55. Martin KR, Reid DM. Is there a role for vitamin D in the treatment of chronic pain? Ther Adv Musculoskelet Dis. 2017 (6):131-135. Published online 2017 May 9. doi:10.1177/ $1759720 X 17708124$ 
56. Hollis BW. Short-term and long-term consequences and concerns regarding valid assessment of vitamin D deficiency: comparison of recent food supplementation and clinical guidance reports. Curr Opin Clin Nutr Metab Care. 2011;14:598-604. doi:10.1097/ MCO.0b013e32834be798

57. Balvers MG, Brouwer-Brolsma EM, Endenburg S. Recommended intakes of vitamin D to optimize health, associated circulation 25 hydroxyvitamin D concentrations, and dosing regimens to treat deficiency: workshop report and overview of current literature. $J$ Nutr Sci. 2015;4:e23. doi:10.1017/jns.2015.10

58. Marziniak M. Kopfschmerzen und Multiple Sklerose. Nervenheilkunde. 2011;7:461-540.

59. Villani V, De Giglio L, Sette G, et al. Determinants of the severity of comorbid migraine in multiple sclerosis. Neurol Sci. 2012;33 (6):1345-1353. doi:10.1007/s10072-012-1119-5

60. Pakpoor J, Handel AE, Giovannoni G, et al. Meta-analyses of the relationship between multiple sclerosis and migraine. PLoS One. 2012;7(9):e45295. doi:10.1371/journal.pone.0045295

61. Gelfand AA, Gelfand JM, Goadsby PJ. Migraine and multiple sclerosis: epidemiology and approach to treatment. Mult Scler Relat Disord. 2013;2(2):73-79. doi:10.1016/j.msard.2012.10.003

62. Buettner C, Rony-Reuven N, Bertisch SM, et al. Simvastatin and vitamin D for migraine prevention: a randomized controlled trial. Ann Neurol. 2015;78(6):970-981. doi:10.1002/ana.24534

63. Scherder R, Kant N, Wolf E, et al. Psychiatric and physical comorbidities and pain in patients with multiple sclerosis. J Pain Res. 2018;11:325-334. doi:10.2147/JPR.S146717

64. Houtchens MK, Edwards NC, Schneider G, et al. Pregnancy rates and outcomes in women with and without MS in the United States. Neurology. 2018. doi:10.1212/WNL0000000000006384

65. Wagner CL, Baggerly C, McDonell S, et al. Post-hoc analysis of vitamin D status and reduced risk of preterm birth in two vitamin D pregnancy cohorts compared with South Caroline March of Dimes 2009-2011 rates. J Steroid Biochem Mol Biol. 2016;155:245-251. doi:10.1016/j.jsbmb.2015.10.022

66. Hollis BW, Wagner CL. Vitamin D supplementation during pregnancy: improvements in birth outcomes and complications through direct genomic alteration. Mol Cell Endocrinol. 2017;453:113-130. doi:10.1016/j.mce.2017.01.039

67. Smolders J, Damoiseaux J, Menheere P, Hupperts R. Vitamin D as an immune modulator in multiple sclerosis, a review. $J$ Neuroimmunol. 2008;194(1-2):7-17. doi:10.1016/j.jneuroim.2007

68. Balbuena LD, Middleton RM, Tuite-Dalton K, et al. Sunshine, sea, and season of birth: MS incidence in Wales. Plose One. 2016

69. Cantorna MT. Vitamin D and multiple sclerosis: an update. Nutr Rev. 2008;66(10Suppl 2):S135-8. pmid:18844840; PubMed Central PMCID: PMCPMC3712128. doi:10.1111/j.17534887.2008.00097.x

70. Hartl C, Obermeier V, Gerdes LA, et al. Seasonal variations of 25$\mathrm{OH}$ vitamin $\mathrm{D}$ serum levels are associated with clinical disease activity in multiple sclerosis patients. J Neurol Sci. 2017;375:160164. doi:10.1016/j.jns.2017.01.059

71. Miclea A, Miclea M, Pistor M, et al. Vitamin D supplementation differentially affects seasonal multiple sclerosis disease activity. Brain Behav. 2017;7(8):e00761. doi:10.1002/brb3.761

72. Holmoy T, Rosjo E, Zetterberg H, et al. Vitamin D supplementation and neurofilament light chain in multiple sclerosis. Acta Neurol Scand. 2018. doi:10.1111/ane.13037

73. Hubeish M, Husari H, Itani SE, et al. Maternal vitamin D level and rate of primary cesarean section. J Clin Gynecol Obstet. 2018;7 (2):43-51. doi:10.14740/jcgo473w

74. Merewood A, Mehta SD, Chen TC, Bauchner H, Holick MF. Association between vitamin D deficiency and primary cesarean section. J Clin Endocrinol Metab. 2009;94(3):940-945. doi: $10.1210 /$ jc. $2008-1217$
75. Saul A, Dance G, Simpson S, et al. Negative, but not positive stressful life events are associated with depression, anxiety and fatigue in people with MS. Mult Scler. 2016;22:(S3);706-827, EP1372.

76. Janssen AB, Savory KA, Garay SM, et al. Persistente of anxiety symptoms after elective caesarean delivery. BJPsych Open. 2018;4 (5):354-360. doi:10.1192/bjo.2018.48

77. Ogino M, Shiozawa A, Ota H, Okamoto S, Hiroi S, Kawachi I. Treatment and comorbidities of multiple sclerosis in an employed population in Japan: analysis of health claims data. Neurodegener Dis Manag. 2018;8:2. doi:10.2217/nmt-2017-0047

78. Koudriavtseva T, Renna R, Plantone D, Mandoj C, Piattella MC, Giannarelli D. Association between Anemia and Multiple Sclerosis. Eur Neurol. 2015;73(3-4):233-237. doi:10.1159/000381212

79. Smith EM, Tangpricha V. Vitamin D and anemia: insights into an emerging association. Curr Opin Endocrinol Diabetes Obes. 2015;22(6):432-438. doi:10.1097/MED.0000000000000199

80. Boehlen F, Hohlfeld H, Extermann P, et al. Platelet count at term pregnancy: a reappraisal of the threshold. Obstet Gynecol. 2000;95:30.

81. Gernsheimer T, James AH, Stasi R. How I treat thrombocytopenia in pregnancy. Blood. 2013;121:38-47. doi:10.1182/blood-2012-08-448944

82. Segal JB, Powe NR. Prevalence of immune thrombocytopenia: analysis of administrative data. J Thromb Haemost. 2006;4:23772383. doi:10.1111/j.1538-7836.2006.02147.x

83. Kirby S, Brown MG, Muray TJ, et al. Progression of multiple sclerosis in patients with other autoimmune disorders [P128]; Prevalence of other autoimmune diseases in patients with multiple sclerosis [P129]. Mult Scler. 2005;11:S28-S9.

84. .[No authors listed]. Practice Bulletin No 166: Thrombocytopenia in Pregnancy. Obstet Gynecol. 2016:128(3):e43-53.

85. Bergmann F, Rath W. The differential diagnosis of thrombocytopenia in pregnancy-an interdisciplinary challenge. Dtsch Arztebl Int. 2015;112:795-802. doi:10.3238/arztebl.2015.0795

86. Fattizzo B, Zaninoni A, Gianotta JA, Binda F, Cortelezzi A, Barcellini W. Reduced $25-\mathrm{OH}$ vitamin $\mathrm{D}$ in patients with autoimmune cytopenias, clinical correlations and literature review. Autoimmun Rev. 2016;15:770-775. doi:10.1016/j.autrev.2016.03.015

87. Bockow B, Bockow-Kaplan T. Refractory immune thrombocytopenia successfully treated with high-dose vitamin D supplementation and hydroxychloroquine: two case reports. J Med Case Rep. 2013;7:91.

88. Schwalfenberg GK. Solar radiation and vitamin D: mitigating environmental factors in autoimmune disease. J Environ Publ Health. 2012. doi:10.1155/2012/619381

89. Liu W, Li H, Hao Y, et al. Decreased immunosuppressive actions of 1-Alpha-25-dihydroxyvitamin D3 in patients with immune thrombocytopenia. Mol Immunol. 2016;78:89-97. doi:10.1016/j. molimm.2016.08.014

90. Morrow SA. Anxiety is more important than depression in MSyes. Mult Scler. 2018.

91. Giovannoni G. Should we rebrand multiple sclerosis a dementia? Mult Scler Relat Disord. 2017;12:79-81. doi:10.1016/j. msard.2017.01.008

92. Gasim M, Bernstein CN, Graff LA, et al. Adverse psychiatric effects of disease-modifying therapies in multiple sclerosis: a systematic review. Mult Scler Relat Disord. 2918;26:124-156. doi:10.1016/j.msard.2018.09.008

93. Fiest KM, Fisk JD, Patten SB, et al. Comorbidity is associated with pain-related activity limitations in multiple sclerosis. Mult Scler Relad Disord. 2015;4:470-476. doi:10.1016/j. msard.2015.07.014

94. Cortese M, Munger KL, Martinez-Lapiscina EH et al. Vitamin D, smoking, EBV and long-term cognitive performance among CIS patients: 11 year follow-up of BENEFIT. Presented at 34th Congress of the European Committee for Treatment and Research in Multiple Sclerosis (ECTRIMS) 2018, Oct 12, Abstract 321. online Library, 232074. 
95. Pettersen JA. Does high dose vitamin D supplementation enhance cognition? A randomized trial in healthy adults. Exp Gerontol. 2017;90:90-97.

96. Gross JH, Watson C. Characteristics, burden of illness, and physical functioning of patients with relapsing-remitting and secondary progressive multiple sclerosis: a cross-sectional US survey. Neuropsychiatr Dis Treat. 2017;13:1349-1357.

97. Lassmann H. Targets of therapy in progressive MS. Mult Scler. 2017;23(12):1593-1599.

98. Kappos L, Bar-Or A, Cree PAC, et al. Siponimod versus placebo in secondary progressive multiple sclerosis (EXPAND): a double-blind, randomized, phase 3 study. Lancet. 2018;391(10127):1263-1273.

99. Pihl-Jensen G, Tsarkiri A, Frederiksen JL. Statin treatment in multiple sclerosis: a systematic review and meta-analysis. CNS Drugs. 2015;29(4):277-291.

100. Filippi M, Rocca MA. Simvastatin and cognition in multiple sclerosis. Lancet Neurol. 2017;16:572-573. doi:10.1016/S14744422(17)30162-X

101. Chan D, Binks S, Nicholas JM, et al. Effect of high-dose simvastatin on cognitive, neuropsychiatric, and health-related quality-of-life measures in secondary progressive multiple sclerosis: secondary analyses from the MS-STAT randomized, placebo-controlled trial. Lancet Neurol. 2017;16:591-600. doi:10.1016/S1474-4422(17) 30113-8

102. Chataway J, Schuerer N, Alsanousi A, et al. Effect of high-dose simvastatin on brain atrophy and disability in secondary progressive multiple sclerosis (MS-STAT): a randomized, placebo-controlled, phase 2 trial. Lancet. 2014;383:2213-2221. doi:10.1016/ S0140-6736(13)62242-4

103. Muris AH, Rolf L, Broen $\mathrm{K}$, et al. A low vitamin D status at diagnosis is associated with an early conversion to secondary progressive multiple sclerosis. J Steroid Biochen Mol Biol. 2016;164:254-257. doi:10.1016/j.jsbmb.2015.11.009

104. Mowry EM, Waubant E, McCulloch C, et al. Vitamin D status predicts new brain MRI activity in multiple sclerosis. Ann Neurol. 2012;72(2):234-240. doi:10.1002/ana.23591

105. Fitzgerald KC, Munger KL, Köchert K, et al. Association of vitamin D levels with multiple sclerosis activity and progression in patients receiving interferon beta-1b. JAMA Neurol. 2015;72 (12):1458-1465. doi:10.1001/jamaneurol.2015.2742

106. Shoemaker TJ, Mowry EM. A review of vitamin D supplementation as disease-modifying therapy. Mult Scler. 2018;24(1):6-11. doi: $10.1177 / 1352458517738131$

107. Pettersen JA. Vitamin D and executive functioning: are higher levels better? J Clin Exp Neuropsychol. 2016;38(4):467-477. doi:10.1080/13803395.2015.1125452

108. Miller KM, Hart PH, de Klerk NH, Davis EA, Lucas RM. Are low sun exposure and/or vitamin D risk factors for type 1 diabetes?. Photochem Photoviol Sci. 2017;16:381. doi:10.1039/C6PP00294C

109. Elmets CA, Cala CM, Xu H. Photoimmunology. Dermatol Clin. 2014;32:277-290. doi:10.1016/j.det.2014.03.005

110. Fajuyigbe D, Young AR. The impact of skin colour on human photobiological responses. Pigment Cell Melanoma Res. 2016;29 (6):607-618. doi:10.1111/pcmr.12511

111. Langer-Gould A, Lucas R, Xiang AH, et al. MS sunshine study: sun exposure but not vitamin D Is associated with multiple sclerosis risk in blacks and hispanics. Nutrients. 2018;10(3):pii:E268. doi:10.3390/nu10030268

112. Rito Y, Flores J, Fernández-Aguilar A, et al. Vitamin D and disability in relapsing-remitting multiple sclerosis in patients with a Mexican background. Acta Neurol Belg. 2018;118(1):47-52. doi:10.1007/s13760-017-0834-3

113. Razaz N, Joseph KS, Boyce WT, et al. Children of chronically ill parents: relationship between parental multiple sclerosis and childhood development health. Mult Scler. 2016;22(11):1452-1462. doi: $10.1177 / 1352458515621624$
114. Moberg JY. Live course of children with parental multiple sclerosis. Dan Med J. 2017;Aug;64(8) pii. B5399.

115. Carlberg C, Haq A. The concept of the personal vitamin D response index. J Steroid Biochemist Mol Biol. 2018;175:12-17. doi:10.1016/j.jsbmb.2016.12.011

116. Pierrot-Deseilligny $\mathrm{CH}$, Souberbielle JD. Vitamin D and multiple sclerosis: an update. Mult Scler Rel Disord. 2017;14:35-45. doi:10.1016/j.msard.2017.03.014

117. Saleh L, Tang J, Gawinecka J, et al. Impact of a single oral dose of $1000,000 \mathrm{IU}$ vitamin D3 on profiles of serum 25(OH)D3 and its metabolites $24,25(\mathrm{OH})^{2} \mathrm{D} 33$-epi-25(OH)D3, and $1,25(\mathrm{OH})^{2} \mathrm{D} 3$ in adults with vitamin D insufficiency. Clin Chem Lab Med. 2017;55 (12):1912-1921. doi:10.1515/cclm-2016-1129

118. Rassaque M. Can adverse effects of excessive vitamin D supplementation occur without developing hypervitaminosis D? J Steroid Biochem Mol Biol. 2017. doi:10.1016/j.jsbmb.2017.07.006

119. Kimbal SM, Ursell MR, O'Connor P, Vieth R. Safety of vitamin D3 in adults with multiple sclerosis. Am J Clin Nutr. 2007;86:645651. doi:10.1093/ajen/86.3.645

120. Valcour A, Blocki F, Hawkins DM, et al. Effects of age and serum 25 $(\mathrm{OH})$-vitamin D on serum parathyroid hormone levels. J Endocrinol Metab. 2012;97(11):398-3995. doi:10.1210/jc.2012-2276

121. Wiendl H, Schwab N, Breuer JH. High-dose vitamin D as adjunctive therapy in the treatment of multiple sclerosis? - an update. German multiple sclerosis society (DMSG), disease-related competence network (KKNMS) [press information]. 2017. Available from https://www.dmsg.de/multiple-sklerose.../hochdosiertes-vita min-d-als-zusatztherapie-in-derBehandlung-der-multiplenSklerose-ein-. Accessed 22 May, 2019.

122. Jones G. Pharmacokinetics of vitamin D toxicity. Am J Clin Nutr. 2008;88(suppl):582S-6S. doi:10.1093/ajen/88.2.582S

123. Jelinek GA, Marck $\mathrm{CH}$, Weiland TJ, et al. Latitude, sun exposure and vitamin D supplementation: associations with quality of life and disease outcomes in a large international cohort of people with multiple sclerosis. BMC Neurol. 2015;15:132. doi:10.1186/s12883015-0394-1

124. Zivadinov R, Raj B, Ramanathan M, et al. Autoimmune comorbidities are associated with brain injury in multiple sclerosis. $\mathrm{Am} \mathrm{J}$ Neuroradiol. 2016;37:1010-1016. doi:10.3174/ajnr.A4681

125. Kalb R, Beier M, Benedict RH, et al. Recommendations for cognitive screening and management in multiple sclerosis care. Mult Scler. 2018. doi:10.1177/1352458518803785

126. Rossi S, Studer V, Motta C, et al. Neuroinflammation drives anxiety and depression in relapsing-remitting multiple sclerosis. Neurology. 2017;89(13). doi:10.1212/WNL.0000000000004411

127. Minden SL, Feinstein A, Kalb RC, et al. Evidence-based guideline: assessment and management of psychiatric disorders in individuals with MS. Neurology. 2014;82:174-181. doi:10.1212 /WNL.0000000000000013

128. Patten SB, Svenson LW, Metz LM. Psychotic disorders in MS: population-based evidence of an association. Neurology. 2005;65:1123-1125. doi:10.1212/01.wnl.0000178998.95293.29

129. Degurud E, Nygard O, de Vogel ST, et al. Plasma 25-hydroxyvitamin D and mortalität in patients with suspected stable angina pectoris. J Clin Endocrinol Metab. 2018;103(3):1161-1170. doi:10.1210/jc.2017-02328

130. Marrie RA, Daumer M. A gestational dose of vitamin D per day keeps the MS doctor away. Neurology. 2017;88:1. doi:10.1212/ WNL.0000000000003693

131. Sintzel MB, Rametta M, Reder AT. Vitamin D and multiple sclerosis: a comprehensive review. Neurol Ther. 2018;7(1):59-85. doi:10.1007/s40120-017-0086-4

132. Schlögl M, Holick M. Vitamin D an neurocognitive function. Clin Interv Aging. 2014;9:559-568.

133. Spiro A, Buttress JL, Vitamin D. An overview of vitamin D status and intake in Europe. Nutr Bull. 2014;39:322-350. 
134. Marck CD, Neate SL, Taylor KL, et al. Prevalence of comorbidities, overweight and obesity in an international sample of people with multiple sclerosis and associations with modifiable lifestyle factors. PLoS One. 2016;11(2):e0148573. doi:10.1371/journal.pone.0148573

135. Marrie RA, Walld R, Bolton JM, et al. Psychiatric comorbidity increases mortality in immune-mediated inflammatory diseases. Gen Hosp Psychiatry. 2018;53:65-72. doi:10.1016/j.genhosppsych.2018.06.001

136. Panda SP, Das RC, Srivastava K, et al. Psychiatric comorbidity in multiple sclerosis. Neurol Neurochir Pol. 2018. doi:10.1016/ pjnns.2018.09.003

137. Zettl U, Eichstadt K, Ellenberger D et al. MS in Deutschland: Symptome und Behandlungsdefizite. [MS in Germany: symptoms and treatment deficits]. NeuroTransmitter. 2018;29(6):42-44. German.

138. Sedal L, Winkel A, Laing J, et al. Current concepts in multiple sclerosis therapy. Degener Neurol Neuromuscul Dis. 2017;7:109125. doi:10.2147/DNND.S109251
139. Edwards NC, Munsell M, Menzin J, et al. Comorbidity in US patients with multiple sclerosis. Patient Relat Outcome Meas. 2018;9:97-102. doi:10.2147/PROM.S148387

140. Lorefice L, Fenu G, Pitzalis R, et al. Autoimmune comorbidities in multiple sclerosis: what is the influence on brain volumes? A casecontrol MRI study. J Neurol. 2018;265(5):1096-1110. doi:10.1007/ s00415-018-8811-1

141. Marrie RA. Comorbidity in multiple sclerosis: implications for patient care. Nat Rev Neurol. 2017;13:375-382. doi:10.1038/nrneurol.2017.33

142. Fond G, Godin O, Schürhoff F, et al. Hypovitaminosis D is associated with depression and anxiety in schizophrenia: results from the national FACE-SZ cohort. Psychiatry Res. 2018;270:104-110. doi:10.1016/j.psychres.2018.09.024

143. McLaughlin L, Clarke L, Khalilidehkordi E, et al. Vitamin d for the treatment of multiple sclerosis. A meta-analysis. J Neurol. 2018. doi:10.1007/s00415-018-9074-6

\section{Publish your work in this journal}

Degenerative Neurological and Neuromuscular Disease is an international, peer-reviewed, open access journal focusing on research into degenerative neurological and neuromuscular disease, identification of therapeutic targets and the optimal use of preventative and integrated treatment interventions to achieve improved outcomes, enhanced survival and quality of life for the patient. The manuscript management system is completely online and includes a very quick and fair peer-review system. Visit http://www.dovepress.com/ testimonials.php to read real quotes from published authors. 